\title{
AVALIAÇÃO MACROSCÓPICA DE IMPACTOS AMBIENTAIS EM NASCENTES DO RIO DE ONDAS NO OESTE DA BAHIA
}

\author{
MACROSCOPIC ASSESSMENT OF ENVIRONMENTAL IMPACTS IN SPRINGS OF THE ONDAS \\ RIVER IN WEST BAHIA
}

\author{
Carla Gisele Dos Santos Carvalho, Rafael Alves PORTO, Uldérico Rios OLIVEIRA \\ Universidade do Estado da Bahia. BR-242, KM 04 s/n - Flamengo, BA, 47802-682. E-mails: \\ carla.1.carvalho@outlook.com; criacaodiversa@gmail.com; eng.ulderico@gmail.com

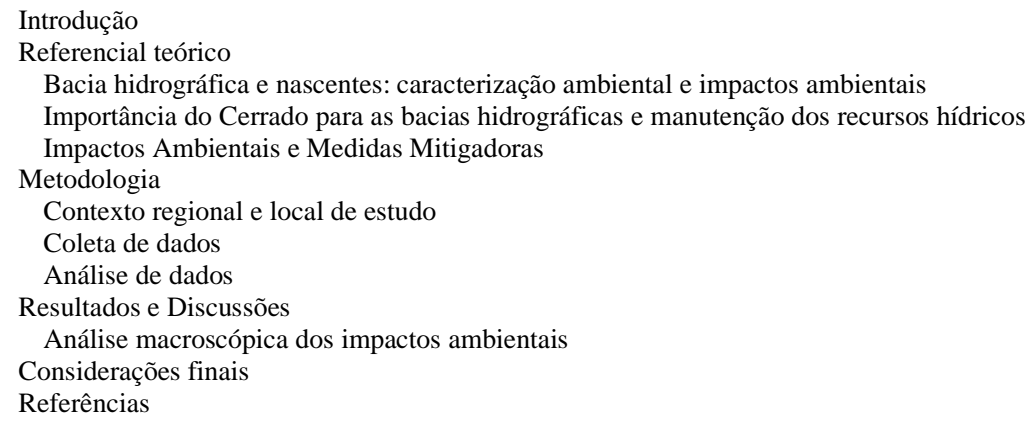

RESUMO - As nascentes são sistemas ambientais singulares que desempenham papel fundamental na conservação e manutenção dos recursos hídricos, em especial na região Oeste da Bahia, onde inúmeras nascentes abastecem rios de importância ambiental e social na região. Desse modo, o presente trabalho busca identificar e avaliar impactos ambientais macroscópicos em nascentes do rio de Ondas, Barreiras - Ba, utilizando técnicas de geoprocessamento e visitas in loco. Os dados obtidos foram processados pelo programa QGIS versão 2.8.l. A partir da aplicação do Índice de Impacto Ambiental em Nascentes, que consiste em um método check-list, foi possível identificar e classificar o grau de preservação das nascentes e discriminar os impactos ambientais recorrentes de ações antrópicas. A análise dos parâmetros revelou que vegetação degradada, queimadas e proximidades à residências foram os impactos mais frequentes e relevantes nas áreas estudadas. Considera-se que a degradação das Áreas de Preservação Permanente ao entorno das nascentes impacta diretamente na preservação das mesmas. Dessa forma, se faz necessário a aplicação de medidas mitigadoras tais como o isolamento da APP com cercas, a retirada de animais de criação das nascentes e o plantio de mudas nativas do Cerrado, uma vez que estas atuam na minimização dos impactos ambientais e recuperação de áreas degradadas.

Palavras-chave: Recursos hídricos; Preservação ambiental; Ações antrópicas.

\begin{abstract}
The water springs are unique environmental systems that play a fundamental role in the conservation and maintenance of water resources, especially in the West region of Bahia, where numerous springs supply rivers of environmental and social importance in the region. Thus, the present paper aims to identify and assess macroscopic environmental impacts on springs of the Ondas river, Barreiras - Ba, using geoprocessing techniques and on-site visits. The data obtained were processed by the QGIS software, version 2.8.l. From the application of the Environmental Impact Index on Springs, which consists of a check-list method, it was possible to identify and classify the degree of preservation of the springs and to discriminate the recurring environmental impacts of anthropic actions. Analysis of the parameters revealed that degraded vegetation, fires and close to homes were the most frequent and relevant impacts in the evaluated areas. The degradation of the Permanent Preservation Areas around the springs is considered to have a direct impact on their preservation. Thus, it is necessary to apply mitigating measures such as the isolation of the APP with fences, the removal of farm animals from the springs and the planting of native Cerrado seedlings, since they act in minimizing environmental impacts and recovering degraded areas.
\end{abstract}

Keywords: Water resources; Environmental preservation; Anthropic actions.

\section{INTRODUÇÃO}

O Brasil é considerado o país com maior disponibilidade hídrica do planeta, porém, apresenta desigualdade em relação a sua distribuição. Dessa forma, áreas demograficamente densas possuem menor disponibilidade hídrica em comparação a áreas menos povoadas, que detém maior concentração e abundância desse recurso (ANA, 2019). Além disso, ao considerar as vazões de todos os rios existentes no mundo (42.600 $\left.\mathrm{km}^{3} / \mathrm{ano}\right)$, cerca de $19 \%$ desse total $\left(8.130 \mathrm{~km}^{3} / \mathrm{ano}\right)$ encontra-se sobre o território brasileiro (Sano et al., 2008; Bandeira \& Campos, 2018).

O Cerrado é o segundo maior bioma brasileiro em extensão territorial, ocupando uma área de $2.036 .448 \mathrm{~km}^{2}$ (MMA, 2020). Localiza-se no Planalto Central brasileiro ocupando uma região de relevância para a conservação dos recursos hídricos por ser o berço de origem das grandes bacias hidrográficas brasileiras e do continente sul-americano, desempenhando papel funda- 
mental na gestão e distribuição dos recursos hídricos do país (Bandeira \& Campos, 2018).

Nos últimos 35 anos, no Oeste Baiano, o bioma Cerrado foi ocupado pelo agronegócio que através de subsídios governamentais promoveram um modelo de agricultura intensiva (Santos et al., 2018).

Com o intenso desenvolvimento foram gerados impactos ambientais ao bioma, ou seja, um desequilíbrio provocado pelo choque da relação do homem com o meio físico, principalmente se tratando do desmatamento e exploração dos recursos hídricos para a irrigação, dessedentação animal e abastecimento humano (Sánchez, 2013).

A partir do uso intensivo dos recursos hídricos pelo agronegócio no Oeste da Bahia, consequências ambientais como a redução da vazão, escassez e desaparecimento dos corpos d'água se intensificaram, uma vez que a presença da pecuária extensiva já era desenvolvida na região antes da implementação da fronteira agrícola (Santos et al., 2018), acarretando impactos relevantes em sua conservação e manutenção.

A água é um recurso natural vital para a sobrevivência humana, manutenção e equilíbrio dos ecossistemas, apresenta-se como um recurso natural renovável, porém finito (Oliveira Neta, 2013). Diante desse fato, deve-se considerar a gestão precária e o uso exaustivo desse bem natural, o qual recebe pressão direta do desmatamento da vegetação nativa que circunda os cursos d'água (Mata Ciliar) e pela falta de fiscalização ambiental em Áreas de Preservação Permanente - APP's.

Ao elaborar práticas de gestão dos recursos hídricos, inicialmente deve se pensar nas nascentes, esses sistemas apresentam papel relevante na preservação e conexão entre os canais superficiais e subterrâneos (Oliveira et al., 2013). Além de agirem como indicadoras da saúde hídrica nas bacias hidrográficas (Pena, 2020).

Uma nascente é definida como um sistema ambiental em que o afloramento da água subterrânea ocorre de modo natural, sendo temporário ou perene e o fluxo hidrológico superficial é integrado a rede de drenagem, culminando na formação de um curso d'água (Felippe \& Magalhães Junior, 2012). Além disso, as nascentes caracterizam por serem APP's. São áreas legalmente protegidas e contribuem na preservação dos recursos hídricos, dos ecossistemas e da biodiversidade, garantindo assim a perpetuação e conservação ambiental desses ambientes (BRASIL, 2012).

Desse modo, a avaliação de impactos ambientais através do IIAN - Índice de Impacto Ambiental em Nascentes (Pieroni et al., 2019), auxiliadas por ferramentas de Sistemas de Informações Geográficas - SIGs, essas capazes de georreferenciar, desenvolver mapas e gerar imagens espaciais no processo de análise ambiental (Alencar et al., 2017), são fundamentais para diagnósticos e elaboração de medidas mitigadoras que visem a recuperação e preservação, bem como o uso sustentável dos recursos hídricos (Neres et al., 2015).

Sendo assim, garantir a preservação das nascentes se torna imprescindível para a conservação dos recursos hídricos, principalmente se referindo a região Oeste da Bahia, onde há rios de grande relevância ambiental e social, os quais contemplam a bacia do rio São Francisco, são responsáveis pelo abastecimento de diversas cidades, promovem a irrigação de culturas, permite o turismo e a subsistência de pescadores. Contudo, destaca-se o rio de Ondas, este abastecido pelas diversas nascentes que afloram nessa região.

A presente pesquisa tem por objetivo avaliar impactos ambientais macroscópicos nas nascentes em visitas in loco e utilizando técnicas de geoprocessamento como ferramentas de identificação desses impactos, elencando possíveis consequências na conservação e manutenção dos recursos hídricos.

\section{REFERENCIAL TÉORICO}

\section{Bacia Hidrográfica e Nascentes: Caracterização e Impactos Ambientais}

A bacia hidrográfica é de suma importância no ciclo hidrológico por ser responsável pela infiltração, escoamento e captação natural da água. Todo curso d'água independentemente do seu tamanho é sempre o resultado da contribuição de determinada área topográfica, que é a sua bacia hidrográfica (Araújo et al., 2009).

Além disso, a capacidade de recarga de uma bacia hidrográfica está relacionada com o relevo e topografia em que está inserida e fatores ambientais ali presentes, estes influenciam na captação de água, formação dos reservatórios subterrâneos e águas superficiais. Fatores como vegetação, a presença de solos porosos ou não e a capacidade do 
solo conter e armazenar água estão intimamente relacionadas com a qualidade, quantidade e manejo dos recursos hídricos numa bacia hidrográfica (SMA, 2009).

A bacia hidrográfica é o resultado de diversos fatores ambientais em conjunto, em decorrência dessa característica ela se torna mais suscetível a alterações ambientais resultantes de ações antrópicas, tais como o desmatamento, uso demasiado do solo, práticas agrícolas intensivas e urbanização sem planejamento (SMA, 2009).

Um subsídio de relevância à gestão das bacias é o reconhecimento dos impactos ambientais negativos presentes. Conforme a resolução CONAMA No 001 de 23 de janeiro de 1986, impacto ambiental é caracterizado por atividades humanas que ocasionam alteração das propriedades físicas, químicas e biológicas do meio ambiente capazes de impactar direto ou indiretamente a saúde; segurança; o bem-estar da população; a biota; a qualidade dos recursos ambientais; as atividades econômicas e sociais e as condições estéticas e sanitárias do meio ambiente (BRASIL, 1986).

Casos, por exemplo, em que há impactos relacionados à poluição sanitária acarretam alterações da qualidade da água, enquanto que a compactação do solo gerado pelo comprometimento da porosidade em decorrência do pisoteio de animais, influencia na infiltração de água, ocasionando déficit na captação e abastecimento dos afluentes, nascentes e cursos d'água que são contemplados por essa bacia (Leal et al., 2017).

A gestão de bacias hidrográficas implica em práticas de preservação da vegetação natural e manejo correto do solo (Soares et al., 2018). Conforme Fistarol et al. (2015) o aumento do uso do solo acarreta impactos como erosão, compactação e entre outros problemas que influenciam e alteram características de uma bacia hidrográfica. Desse modo, a gestão dessas áreas implica em manejo e atividades que reduzam a compactação do solo, uma vez que a qualidade do solo interfere na recarga e infiltração superficial d’água.

Diante disso, as nascentes por serem o resultado da infiltração de uma bacia hidrográfica e responsáveis por originar os cursos d'águas são fundamentais na caracterização e gestão das mesmas (Gomes et al., 2018).

Uma nascente pode ser compreendida como o afloramento de um aquífero, sendo esse afloramento do tipo perene (de fluxo contínuo) ou temporário (de fluxo sazonal) (SEMA, 2010; Leal et al., 2017). Podem ser classificadas quanto à disposição no terreno, ou seja, difusa quando essa nascente apresenta vários pontos de afloramento, típica em áreas alagadas do Cerrado como as veredas e, pontual, quando a nascente apresenta apenas um ponto principal e concentrado de afloramento superficial d'água (SEMA, 2010).

As nascentes são imprescindíveis para a manutenção do equilíbrio hidrológico e ambiental das bacias hidrográficas (Felippe \& Magalhães Junior, 2012). Para Oliveira et al. (2013) a nascente é vista como um sistema singular e o ponto de partida para a realização das práticas de gestão dos recursos hídricos, pois este sistema é o responsável pela conexão entre a água subterrânea e a superfície terrestre.

Para tanto, o sistema em que a nascente está inserida deve ser preservado, sendo esse constituído pela vegetação nativa, solo, rochas e relevo das áreas adjacentes (Gomes et al., 2005). Sendo assim, as nascentes, independente de qual seja sua localização, de acordo a Lei Federal $n^{\circ}$ 12.651/12 - Código Florestal, são consideradas Áreas de Preservação Permanente (APP's), sendo necessária a preservação de uma área com raio mínimo de 50m ao seu entorno (BRASIL, 2012).

Ressalta-se que em propriedades rurais que possuam consolidada atividades agrossilvipastoris, turismo, ecoturismos rurais dentro de APP's até o período de 22 de julho de 2008, é obrigatório a recomposição natural da vegetação em uma área com raio mínimo de 15m (BRASIL, 2012).

Através da delimitação e isolamento dessa área é possível assegurar menor interferência humana, restringir o acesso de animais que possam causar pisoteio e compactação ao solo, além de permitir maior proteção a vegetação natural, solo e características topográficas (SENAR, 2015).

O sistema hidroambiental em que a nascente está inserida apresenta fragilidade considerável, e mínimas alterações em seu fluxo, ocasionadas por alterações antrópicas geram impactos e comprometimentos significativos na qualidade da água (Oliveira et al., 2013).

Segundo Felippe \& Magalhães Junior (2012) uma das principais consequências das intervenções urbanas na dinâmica das nascentes são as alterações de vazão, o que acarreta em muitos casos no desaparecimento da nascente ou alteração em seu perfil transformando-a em nascente temporária. Já a ausência de proteção ao redor das nascentes também pode facilitar o fluxo de pessoas e animais, ocasionando o pisoteio e por consequência, alte- 
ração na vazão das nascentes (Leal et al., 2017).

De acordo Araújo et al. (2009) outros impactos ambientais que ocasionam a contaminação dos corpos hídricos e do solo estão relacionados as técnicas agrícolas inadequados, o uso incorreto dos recursos naturais, o desmatamento e a utilização de agroquímicos. Variáveis naturais como a geologia, a cobertura vegetal, o regime de chuvas, o lançamento de efluentes domésticos e o manejo inadequado do solo refletem diretamente na qualidade da água superficial e subterrânea (ANA, 2019).

Segundo Araújo et al. (2009), muitos indivíduos não possuem consciência da necessidade de conservação do meio onde vivem, e áreas de nascentes que apresentam grande sensibilidade sofrem com maior grau de impacto ambiental.

\section{Importância do Cerrado para as Bacias Hidrográficas e Manutenção Dos Recursos Hídricos}

O bioma Cerrado, por ocupar boa parte do Planalto Central do Brasil e possuir áreas disjuntas, desempenha papel fundamental na distribuição de água pelo país, sendo responsável por contribuir na produção hídrica de seis das oito grandes bacias hidrográficas, sendo a Bacia Amazônica, Bacia do Tocantins, Bacia Atlântico Norte/Nordeste, Bacia do São Francisco, Bacia Atlântico Leste e a Bacia Paraná/Paraguai (Sano et al., 2008). Além disso, regiões a montante dessas bacias como nascentes e cabeceiras estão presentes nesse bioma. Segundo Sano et al. (2008), outro aspecto que influencia na hidrologia é a característica do Cerrado ser rodeado por vários ecossistemas.

O principal uso de água no Brasil de acordo a Agência Nacional de Água - ANA em termos de quantidade utilizada é a irrigação (49,8\%) advinda de práticas agrícolas, em seguida pelo abastecimento humano (24,4\%) e pela indústria (9,6\%). Nas últimas duas décadas houve um aumento na retirada de água em $80 \%$ e até 2030 a estimativa é que haja um aumento de $26 \%$ no uso de água no país (ANA, 2019).

A região Oeste da Bahia, composta por 22 municípios, está localizada em maior parte no bioma Cerrado e apresenta duas bacias hidrográficas com sistemas fluviais de relevância para o equilíbrio ambiental da região, sendo elas afluentes da margem esquerda do rio São Francisco - a do rio Corrente e a do rio Grande (Reis, 2014). Segundo Magalhães \& Brasileiro (2017), a região Oeste da Bahia encontra-se sobre o aquífero Urucuia, um dos mais importantes do Brasil e responsável pela recarga de toda a bacia hidrográfica da região (Figura 1).

A bacia do rio de Ondas (Figura 2), afluente do rio Grande, compreende uma área aproximada de $5.580,6 \mathrm{~km}^{2}$ abrangendo os municípios de Barreiras e Luís Eduardo Magalhães (Almeida et al., 2016). Conforme o autor, a bacia hidrográfica do rio de Ondas sofre com impactos ambientais, principalmente o desmatamento e a erosão do solo, estes ocasionados a partir da expansão da fronteira agrícola no Cerrado do Oeste baiano.

Em estudo realizado por Magalhães \& Brasileiro (2017), a bacia do rio de Ondas vem sofrendo exploração dos seus recursos hídricos de modo intensivo a partir da migração sulista ocasionada na década de 1970 a qual permitiu a abertura de grandes fazendas agrícolas, consequentemente inseriu-se um modo de produção de alto impacto ambiental.

A bacia hidrográfica do rio Grande, está situada no estado da Bahia com uma área territorial aproximada de $75.000 \mathrm{~km}^{2}$. Tem sua nascente entre a divisa dos estados da Bahia e Goiás e percorre 502 km até desaguar no rio São Francisco. Representa $12,6 \%$ da drenagem do rio São Francisco, sendo a sua maior sub-bacia. Ao decorrer desta bacia hidrográfica é observado conflitos pelo uso da água, remetendo a necessidade de planejamento e gestão dos recursos hídricos (Moreira \& Silva, 2010).

A expansão da fronteira agrícola no Cerrado e a migração interna nas décadas de 1970 e 1980 contribuíram para o desenvolvimento de impactos ambientais caracterizados pelo desmatamento, por processos erosivos intensificados e pela contaminação dos recursos hídricos (Conejo et al., 2005). Segundo Reis (2014) neste contexto, a vegetação de cerrados no Oeste da Bahia vem sendo reduzida brutalmente em favor da implantação de atividades agrícolas modernas, do uso exaustivo das águas subterrâneas através da implantação de poços artesianos para a irrigação por pivô com cerca de 14,7\% de ocupação no Oeste Baiano (ANA, 2019), proporcionando sérios impactos ao ambiente natural e pressão sobre o aquífero e consequentemente em sua rede de drenagem.

Um aspecto apontado por Faleiro \& Faria (2008) é que a partir da entrada de diversas monoculturas no Cerrado como a soja e milho houve uma demanda adicional no uso da água, principalmente no município de Barreiras - Ba, onde o regime de chuvas não é adequado ou constante para essas culturas. 


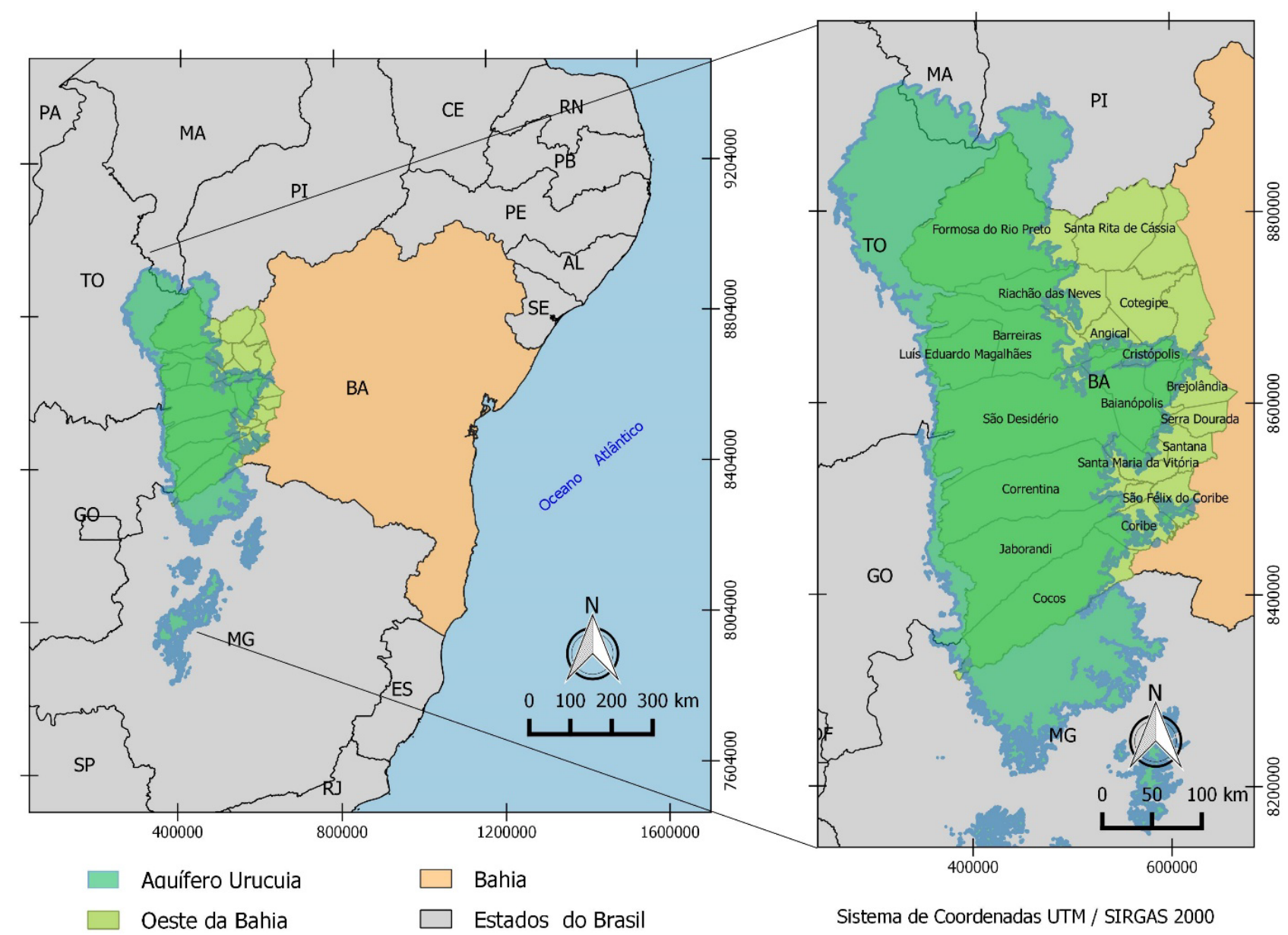

Figura 1 - Mapa de localização do sistema aquífero Urucuia.

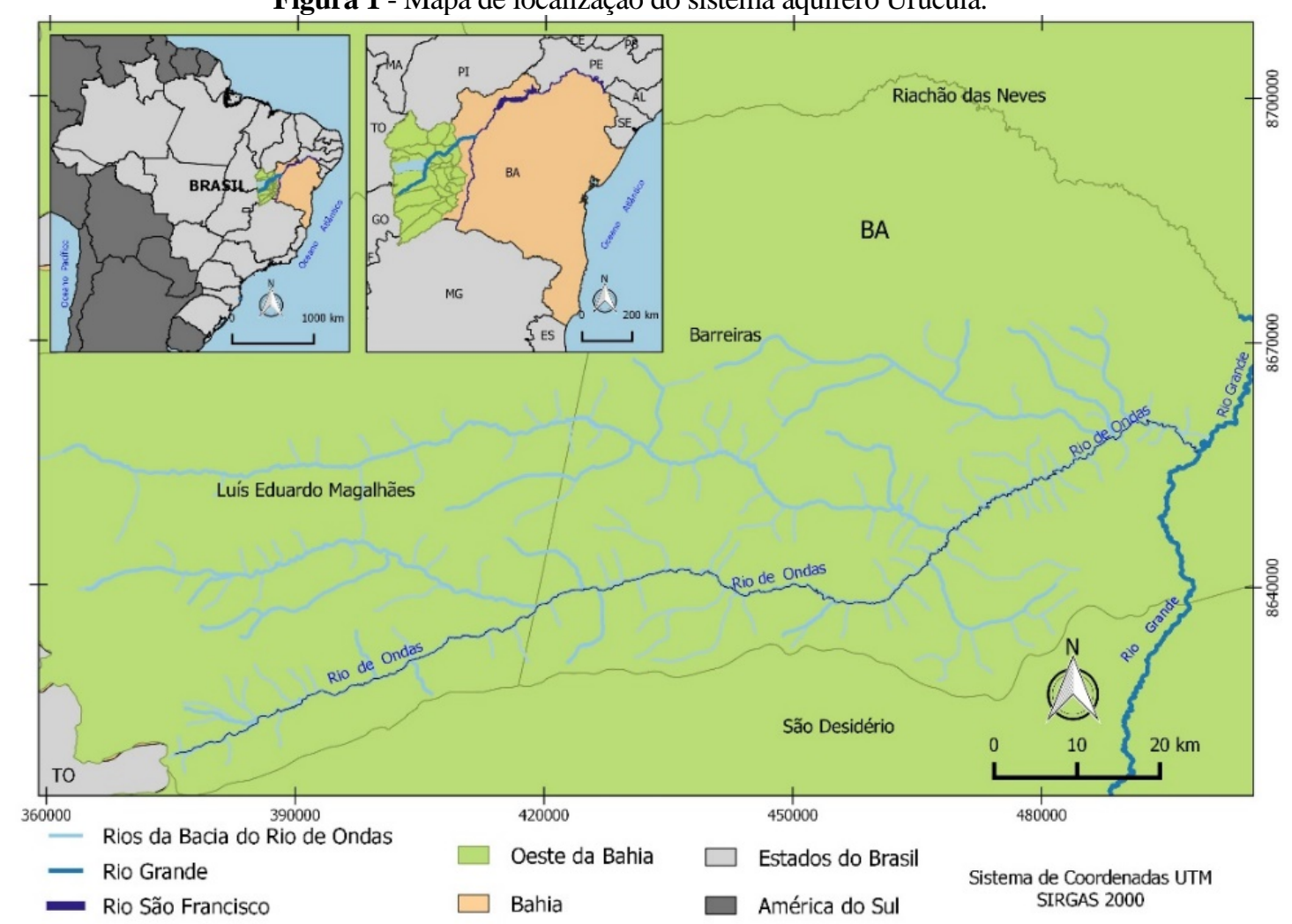

Figura 2 - Mapa da localização da bacia do rio de Ondas.

Além disso, a pesquisa desenvolvida por relataram que a bacia do rio de Ondas sofre Magalhães \& Brasileiro (2017) na comunidade do impactos gerados pelo avanço do agronegócio, Val da Boa Esperança - Barreiras - Ba, moradores como o uso exacerbado da água para irrigação que 
acarreta a diminuição da vazão e a contaminação da bacia e logo das nascentes por meio da lixiviação de agroquímicos presentes no solo.

Assim, as regiões de nascentes que são abastecidas por bacias hidrográficas ao longo do bioma Cerrado, devido apresentarem menor capacidade de suporte e diluição de poluentes, estão mais sujeitas à contaminação, a restrição de vazão e à ocorrência de conflitos pelo uso da água (Sano et al., 2008).

\section{Impactos Ambientais e Medidas Mitigadoras}

É considerado impacto ambiental, segundo a Resolução CONAMA No 001, de 23 de janeiro de 1986, qualquer alteração das propriedades físicas, químicas e biológicas do meio ambiente, gerada por qualquer forma de matéria ou energia resultante das ações antrópicas (BRASIL, 1986).

Impacto ambiental pode ser compreendido segundo Sánchez (2013) como alterações ambientais em determinada área ou região, decorrentes de atividades antrópicas presentes ou passadas, que acarretam algum impacto ambiental negativo.

Para Sobral et al. (2007), a avaliação de impactos ambientais compreende parâmetros qualitativos que podem ser definidos como: frequência, reversibilidade, extensão, duração, origem, sentido e grau de impacto.

Conforme Cremonez et al. (2014), a avaliação de impactos ambientais compreende métodos capazes de subsidiar o estudo de fatores determinantes de alterações ambientais, seja eles positivos ou negativos.

De acordo a Felippe \& Magalhães Junior (2012) os impactos ambientais mais recorrentes ao entorno das nascentes são gerados pela substituição da vegetação nativa de suas margens para construção civil, inerente ao avanço urbano das grandes cidades. Porém, na zona rural os impactos estão relacionados a retirada da vegetação nativa para introdução de pastagem e culturas, tanto em grande escala quanto em pequena escala (Souza et al., 2016).

Medidas mitigadoras são ações que tem por finalidade reduzir a magnitude e a importância dos impactos ambientais negativos (Sánchez, 2013). Podem ser subdivididas em medidas mitigadoras corretivas (reconstrução de um cenário após um evento danoso); medidas mitigadoras preventivas (minimiza eventuais impactos provenientes de determinada ação antrópica); medidas mitigadoras compensatórias (ações que visam recompor e compensar perturbações ao ambiente); e medidas potencializadoras (maximizam efeitos positivos), ressalvando que devem estar vinculadas ao planejamento e monitoramento ambiental (Zeferino, 2018).

Para Neres et al. (2015), medidas mitigadoras subsidiam ações de caráter corretivo, uma vez que funcionam como um conjunto de ações e técnicas de recuperação de áreas ambientais impactadas negativamente. Segundo Araújo et al. (2009) com medidas de manejo adequadas e ações mitigadoras, é possível recuperar áreas impactadas proporcionando a melhora na qualidade da água, combate e controle da poluição ambiental.

De acordo Souza et al. (2016) algumas ações mitigadoras podem ser usadas em áreas que sofrem impactos ambientais e degradação, como isolamento da área, para evitar a entrada de pessoas e animais, a retirada de espécies exóticas próximo aos corpos d'água, e a indução da regeneração natural da vegetação.

\section{MATERIAIS E MÉTODOS}

\section{Contexto Regional e Local de Estudo}

O município de Barreiras está localizado na região Oeste da Bahia (Figura 3 ), entre as coordenadas $11^{\circ} \mathrm{S}$ e $46^{\circ} 30^{\prime} \mathrm{W}$ e $14^{\circ} \mathrm{S}$ e $43^{\circ} 30^{\prime}$ $\mathrm{W}$, com extensão territorial de $7.861,762 \mathrm{~km}^{2}$ (IBGE, 2017). Apresenta três bacias hidrográficas (Grande, Corrente e Carinhanha) todas afluentes do rio São Francisco (Batistella et al., 2002).

Essa região apresenta o período chuvoso entre outubro e março e o período seco, com déficit hídrico, de abril a setembro (Santana et al., 2010). O máximo comum e precipitações de mínimo variam nas direções oriental-ocidentais de 800 para $1.600 \mathrm{~mm} /$ ano. O Cerrado é a fisionomia dominante e, em geral, correlacionado ao relevo plano e solos do tipo Latossolo Vermelho-Amarelo e Neossolo Quartzarênico. Ao longo dos rios e córregos, como também sobre os solos aluviais sujeitos a inundações periódicas, observam-se formações de matas ciliares (Batistella et al., 2002).

A pesquisa foi desenvolvida em uma porção da bacia do rio de Ondas, o qual tem situado sua nascente na Serra Geral, divisa entre os estados de Tocantins e Goiás. Apresenta extensão de 175 $\mathrm{km}$, nesse perímetro o relevo característico é o planalto, além da presença de depressões ao se aproximar do encontro do rio Grande (Magalhães \& Brasileiro, 2017). 

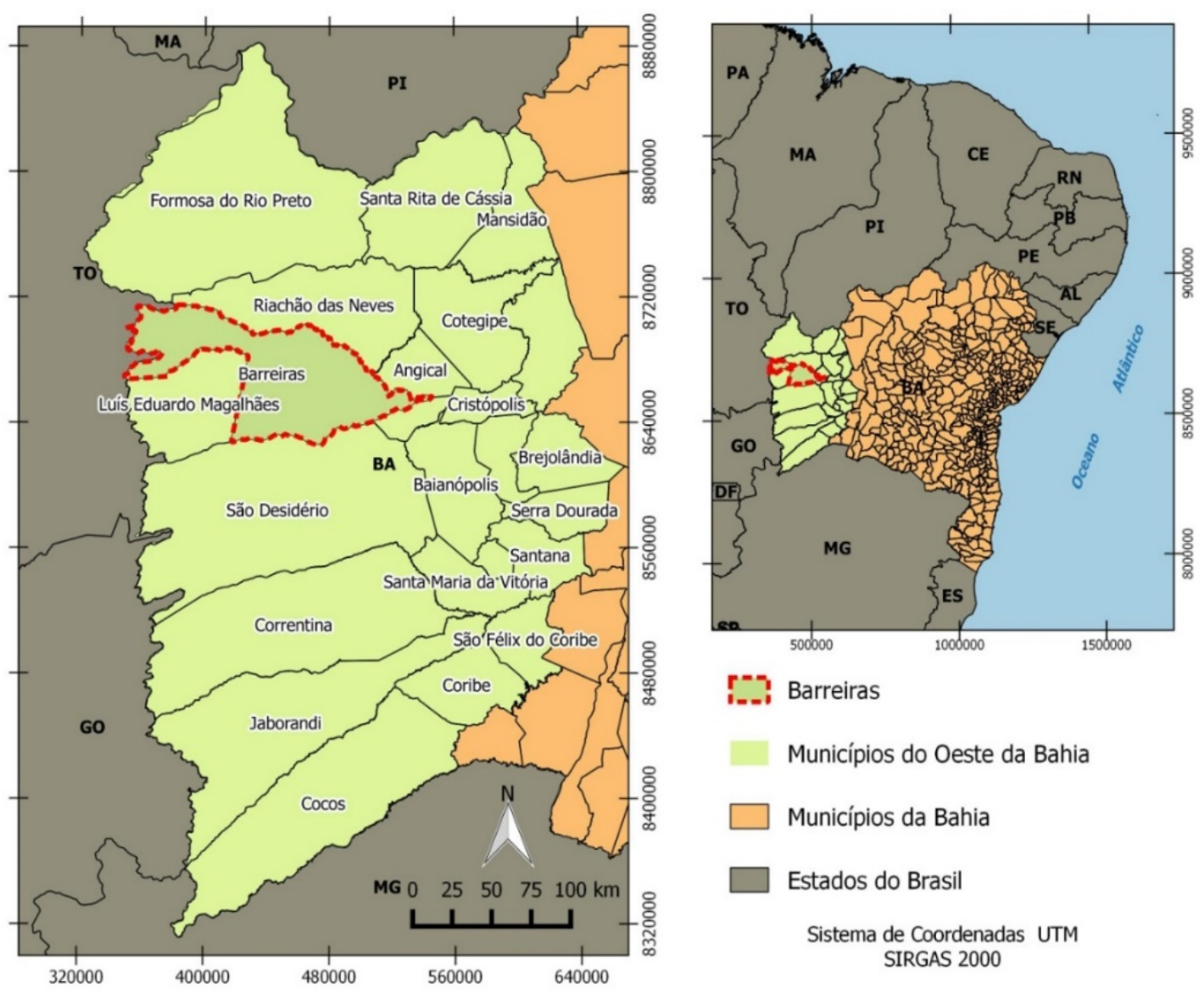

Figura 3 - Imagem da localização e limites territoriais de Barreiras - BA.

\section{Coleta de Dados}

Foram coletadas informações sobre os impactos ambientais às nascentes através de visitas in loco, tais como a presença de materiais flutuantes e lixo ao redor, esgoto, uso por animais, vegetação, queimadas e entre outros. Durante os meses de novembro e dezembro de 2019, período que corresponde ao início da estação chuvosa na região. Utilizouse o GPS - Global Positioning System, tipo navegação - GARMIM/ETREX H e posteriormente, suas coordenadas geográficas foram transferidas para aplicativo SIG, base cartográfica contendo, hidrografia, rodovias, e divisão territorial (IBGE, 2010; INCRA, 2010; MMA, 2010), para o mapeamento das nascentes, no sistema QGIS versão 2.8.1 e Google Earth.

As localizações iniciais das nascentes foram obtidas através da Secretaria Municipal de Meio Ambiente e Turismo - SEMATUR, Barreiras BA e a partir de relatos de agricultores familiares da bacia do rio de Ondas e georreferenciadas. Foram selecionadas para análise ambiental 13 nascentes, onde o critério de seleção baseou-se no fácil acesso ao local e por estarem inseridos na bacia do rio Ondas.

\section{Análise de Dados}

Para a avaliação dos impactos ambientais macroscópicos nas nascentes, utilizou-se o método IIAN - Índice de Impacto Ambiental em Nascentes, proposto por Gomes et al. (2005), sendo adaptado do Guia de Avaliação da Qualidade das Águas (2004) e, corroborados por Felippe \& Magalhães Junior (2012), Leal et al. (2017) e Pieroni et al. (2019). A partir do método IIAN, foram adaptados 12 (doze) parâmetros macroscópicos, descritos na tabela 1 . Os parâmetros foram submetidos a uma avaliação, cada parâmetro apresenta três diferentes atributos que devem ser avaliados e observados in loco. Cada atributo correspondente a um cenário a ser observado em campo, foi atribuído um peso que varia de um a três, sendo 1 para o cenário que apresenta maiores impactos e alterações em função de ações antrópicas, peso 2 para o local com baixo índice de impacto ambiental e 3 para cenários que apresentem alto grau de preservação e menor interferência antrópica (Pieroni et al., 2019).

Os dados obtidos através da avaliação dos parâmetros macroscópicos in loco foram quantificados (soma dos atributos obtidos em cada parâmetro) e classificados em cinco classes (Tabela 2). 
Cada classe apresenta o grau de preservação identificado nas nascentes, sendo a classe A (pontuação máxima de 36 pontos) com o melhor estado de preservação e a classe E (pontuação mínima de 12 pontos) o pior estado de preservação.

Tabela 1 - Parâmetros macroscópicos e peso dos atributos.

\begin{tabular}{|c|c|c|c|}
\hline \multirow{2}{*}{$\begin{array}{c}\text { Parâmetros } \\
\text { Macroscópicos }\end{array}$} & \multicolumn{3}{|c|}{ Atributos } \\
\hline & Peso 1 & Peso 2 & Peso 3 \\
\hline Cor da água & Escura & Clara & Transparente \\
\hline Odor & Odor forte & Odor fraco & Sem odor \\
\hline Lixo ao redor & Muito & Pouco & Sem lixo \\
\hline Materiais flutuantes & Muito & Pouco & Sem material flutuante \\
\hline Indícios de queimada & Muito & Pouco & Ausente \\
\hline Esgoto & Esgoto doméstico & Fluxo superficial & Ausente \\
\hline Vegetação & Alta degradação & Baixa degradação & Preservada \\
\hline Uso por animais & Presença & Indícios de rastros & Ausente \\
\hline Uso antrópico & Presença & Indícios de rastros & Ausente \\
\hline Proteção & Sem proteção & $\begin{array}{c}\text { Com proteção/ havendo } \\
\text { acesso humano }\end{array}$ & $\begin{array}{l}\text { Com proteção/ sem } \\
\text { acesso humano }\end{array}$ \\
\hline $\begin{array}{l}\text { Proximidades às } \\
\text { residências }\end{array}$ & Menos de 50m & Entre 50 e $100 \mathrm{~m}$ & Acima de $100 \mathrm{~m}$ \\
\hline $\begin{array}{c}\text { Tipos de área de } \\
\text { inserção }\end{array}$ & Ausente & Propriedades privadas & $\begin{array}{l}\text { Parques ou áreas } \\
\text { protegidas }\end{array}$ \\
\hline
\end{tabular}

Fonte: Adaptado de Gomes et al. (2005) e Felippe e Magalhães Junior (2012).

Tabela 2 - Classificação das nascentes quanto aos impactos macroscópicos (somatória dos pontos obtidos).

\begin{tabular}{c|c|c} 
Classe & Grau de Preservação & Pontuação final \\
\hline A & Ótima & $33-36$ \\
\hline B & Boa & $30-32$ \\
\hline C & Razoável & $27-29$ \\
\hline D & Ruim & $24-26$ \\
\hline E & Péssima & $0-23$
\end{tabular}

Fonte: Adaptado de Gomes et al. (2005) e Felippe e Magalhães Junior (2012).

Os dados analisados foram apresentados em um mapa temático, através da interpolação espacial dos dados obtidos a partir da avaliação dos impactos ambientais macroscópicos nas nascentes, aplicando o método de Ponderação pelo Inverso de Distancia - IDW, processados no QGIS.

A interpolação espacial é o processo de utilização de pontos com valores conhecidos para estimar os valores em outros pontos desconhecidos.

No método IDW de interpolação as amostras de pontos são passadas durante a interpolação de acordo com a influência de um ponto relativo a outro declinado com a distância a partir de um ponto desconhecido que você quer criar (QGIS, 2020).

\section{RESULTADOS E DISCUSSÕES}

Análise Macroscópica dos Impactos Ambientais

A partir da análise in loco foi possível mensurar o grau de impactos ambientais macroscópicos em 13 (treze) nascentes e georreferenciá-las. As nascentes estão distribuídas em sete comunidades ribeirinhas da bacia do rio de Ondas, as quais captam água do rio e de algumas nascentes para consumo, abastecimento, irrigação para agricultura familiar e dessedentação de animais. O mapa (Figura 4) apresenta a distribuição espacial das nascentes, as comunidades em que se localizam e quantas nascentes foram identificadas em cada comunidade, sendo: Sumidouro (02 nascentes), Sucuriú (01 nascente), Cabeceira Grande (02 nascentes), Fazendinha (01 nascente), Val da Boa Esperança (02 nascentes), Riacho de Areia (02 nascentes) e Mucambinho (03 nascentes).

As nascentes estão inseridas em sua maioria em área de veredas e buritizal, por consequência se caracterizam em nascentes difusas.

Os valores obtidos a partir da aplicação do método IIAN nas nascentes estão apresentados na tabela 3, nela é possível observar o peso aplicado a cada atributo nos respectivos parâmetros. Na figura 6 é possível observar no mapa de interpolação os cincos níveis de classificação do Grau de Preservação das Nascentes, essa classificação se refere aos resultados dos parâmetros avaliados no método IIAN. 


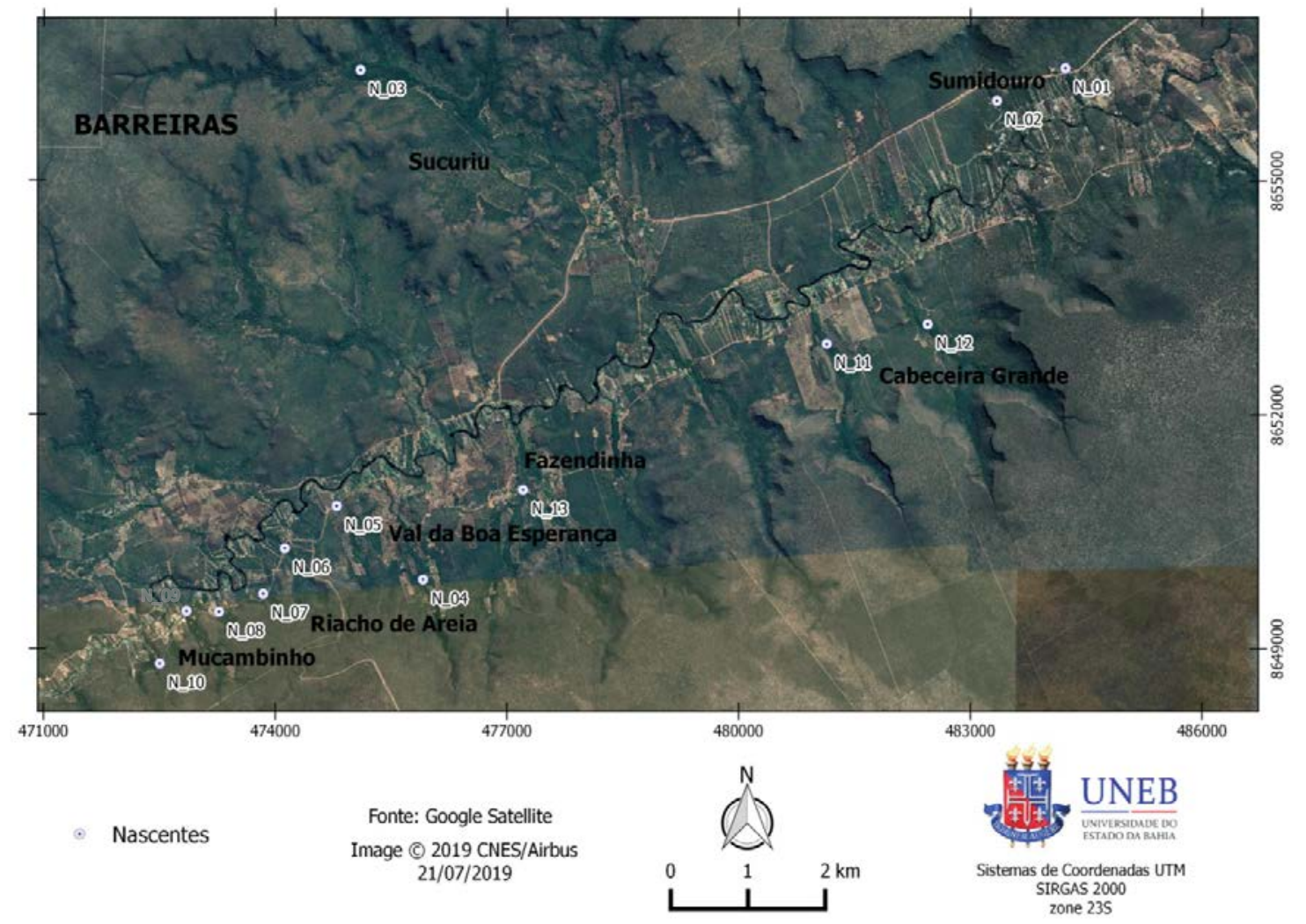

Figura 4 - Mapa da distribuição espacial das nascentes identificadas e comunidades as quais pertencem respectivamente.

Com base nos parâmetros avaliados, os resultados em relação ao estado de preservação das nascentes se mostra em sua maioria de baixa degradação, o que denota interferência de ações antrópicas nessas áreas de baixa intensidade, uma vez que as atividades presentes nas comunidades exercem baixa pressão nos recursos naturais, sendo característica da agricultura familiar de subsistência.

Entretanto, há nascentes com alto nível de degradação, tendo como principais fatores a ocorrência de incêndios indiscriminados, pecuária e o surgimento de novas estradas rurais em áreas de APP. O que demonstra a falta de informação referente a práticas de manejo sustentável ao entorno das nascentes, sendo indispensável a aplicação de medidas mitigadoras na redução dos impactos ambientais em associação a um Plano de Recuperação de Áreas Degradadas - PRAD.

De acordo ao mapa de interpolação (Figura 5) cerca de $69,2 \%$ das nascentes em destaque na coloração azul apresentam o maior grau de preservação e pertencem às classes ótima - A (nascentes: 12 - 33 pontos; $03-34$ pontos) 15,3\%, boa - B (nascentes: $02-30$ pontos; 04 32 pontos; 07 - 31 pontos; $10-32$ pontos; 11 32 pontos; 13 - 31 pontos) 46,1\%, e razoável - C (nascente: 05 - 29 pontos) 7,6\%. No entanto,
$30,7 \%$ das nascentes em destaque na coloração vermelha estão classificadas como ruim - D (nascentes: $06-26$ pontos; $08-24$ pontos) $15,3 \%$, e péssimo - $E$ (nascentes: $01-12$ pontos; $09-21$ pontos) $15,3 \%$.

Ao observar o mapa gerado a partir da metodologia de interpolação, obtêm-se uma avaliação que expressa características de intensidade quanto as áreas preservadas em relação as áreas que apresentam maior degradação ambiental. Assim, o método consiste no produto final do processo de interpolação e a distribuição espacial do grau de preservação na área estudada, a partir do método de Ponderação pelo Inverso de Distancia - IDW.

Desse modo, a figura 6 discrimina os percentuais dos parâmetros em relação aos pesos dos atributos.

Os parâmetros cor da água, odor, lixo ao redor, materiais flutuantes e esgoto estiveram ausentes de impactos respectivamente em 69\%, $85 \%$ e $92 \%$ das nascentes avaliadas como demostra a figura 7. Apenas 23\% das nascentes (nascentes 06, 07 e 09) apresentaram alteração na coloração da água e $8 \%$ das nascentes (nascente 09) apresentou a presença de lixo, materiais flutuantes e alteração no odor, porém em menor intensidade. Nas demais nascentes não foi observado a presença desses parâmetros. Como 
se trata de uma zona rural a região em que as nascentes estão inseridas e consequentemente

apresentar baixa densidade populacional, explicaria a menor ocorrência desses impactos.

Tabela 3 - Quantificação das análises dos parâmetros macroscópicos de 13 nascentes e classificação do grau de preservação.

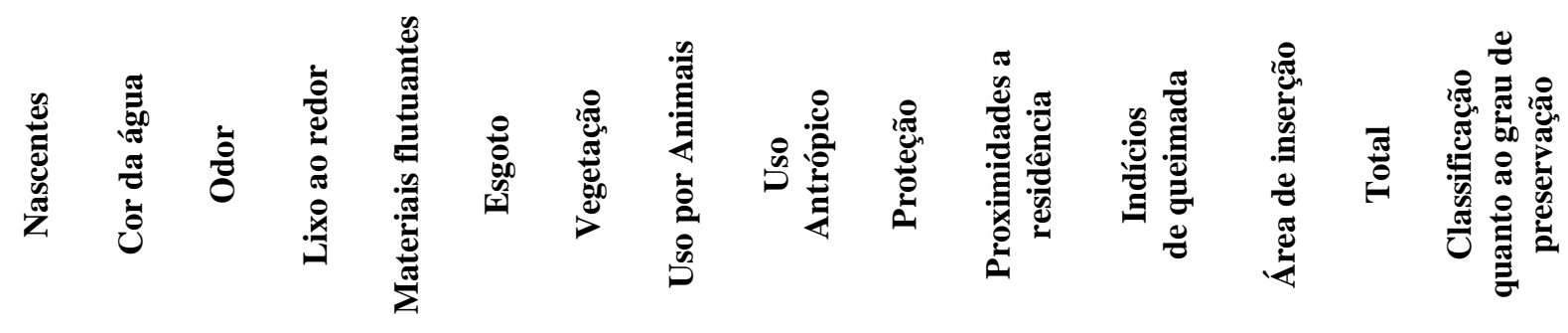

\begin{tabular}{lllllllllllllll}
\hline $\mathbf{0 1}$ & $*$ & $*$ & $*$ & $*$ & $*$ & 1 & 3 & 2 & 2 & 1 & 1 & 2 & $\mathbf{1 2}$ & $\mathbf{E}$ \\
\hline $\mathbf{0 2}$ & 3 & 3 & 3 & 3 & 3 & 2 & 3 & 2 & 3 & 2 & 1 & 2 & $\mathbf{3 0}$ & $\mathbf{B}$ \\
\hline $\mathbf{0 3}$ & 3 & 3 & 3 & 3 & 3 & 3 & 2 & 3 & 3 & 3 & 3 & 2 & $\mathbf{3 4}$ & $\mathbf{A}$ \\
\hline $\mathbf{0 4}$ & 3 & 3 & 3 & 3 & 3 & 3 & 2 & 2 & 2 & 3 & 3 & 2 & $\mathbf{3 2}$ & $\mathbf{B}$ \\
\hline $\mathbf{0 5}$ & 3 & 3 & 3 & 3 & 3 & 2 & 1 & 2 & 2 & 2 & 3 & 2 & $\mathbf{2 9}$ & $\mathbf{C}$ \\
\hline $\mathbf{0 6}$ & 2 & 3 & 3 & 3 & 3 & 2 & 2 & 2 & 2 & 1 & 1 & 2 & $\mathbf{2 6}$ & $\mathbf{D}$ \\
\hline $\mathbf{0 7}$ & 2 & 3 & 3 & 3 & 3 & 3 & 2 & 2 & 2 & 3 & 3 & 2 & $\mathbf{3 1}$ & $\mathbf{B}$ \\
\hline $\mathbf{0 8}$ & 3 & 3 & 3 & 3 & 3 & 1 & 1 & 1 & 2 & 1 & 1 & 2 & $\mathbf{2 4}$ & $\mathbf{D}$ \\
\hline $\mathbf{0 9}$ & 2 & 2 & 2 & 2 & 3 & 1 & 2 & 1 & 2 & 1 & 1 & 2 & $\mathbf{2 1}$ & $\mathbf{E}$ \\
\hline $\mathbf{1 0}$ & 3 & 3 & 3 & 3 & 3 & 3 & 2 & 3 & 1 & 3 & 3 & 2 & $\mathbf{3 2}$ & $\mathbf{B}$ \\
\hline $\mathbf{1 1}$ & 3 & 3 & 3 & 3 & 3 & 3 & 2 & 2 & 2 & 3 & 3 & 2 & $\mathbf{3 2}$ & $\mathbf{B}$ \\
\hline $\mathbf{1 2}$ & 3 & 3 & 3 & 3 & 3 & 3 & 2 & 2 & 3 & 3 & 3 & 2 & $\mathbf{3 3}$ & $\mathbf{A}$ \\
\hline $\mathbf{1 3}$ & 3 & 3 & 3 & 3 & 3 & 2 & 2 & 2 & 2 & 3 & 3 & 2 & $\mathbf{3 1}$ & $\mathbf{B}$
\end{tabular}

*: Parâmetro não mensurável devido à ausência de fluxo d’água na nascente.

Peso 1: alta degradação resultante de ações antrópicas; peso 2: baixo grau de impacto ambiental; peso 3: alto grau de preservação ambiental.

Classificação quanto ao grau de preservação: classe A: ótimo; classe B: boa; classe C: razoável; classe D: ruim; classe E: péssimo.

No estudo realizado por Leal et al. (2017) em nascentes da Floresta Nacional de Capão Bonito e propriedades rurais, nenhum impacto relacionado a alteração da água e a presença de lixo ou materiais flutuantes foram encontrados, mesmo em nascentes de fácil acesso.

Já Pieroni et al. (2019) notou alteração na cor da água em $18 \%$ das nascentes, a turbidez da água foi associada a presença de processos erosivos ao entorno das nascentes, diferente de outros estudos que associaram a turbidez a efluentes lançados nos canais superficiais.

Porém, nas nascentes em que apresentaram impactos ambientais provenientes desses parâmetros, a localização próxima a estradas e residências influenciaram diretamente, a figura 7 mostra a coloração turva da água, presença de lixo (nascente 09) e residências próximas (nascentes 01, 02, 05, 06, 08 e 09).

Em pesquisa realizada por Oliveira et al.
(2013) as nascentes também apresentaram grande quantidade de materiais flutuantes e lixo nas áreas de afloramento, sendo corroborado por Gomes et al. (2005) que em estudo realizado em 16 nascentes próxima a área urbana de Uberlândia - MG, detectou a presença de grande quantidade de lixo, matérias flutuantes e óleos, sendo estes indicativos de poluição sanitária.

Em relação a vegetação, 23\% das nascentes apresentaram alto nível de degradação (nascentes 01, 08 e 09) e $31 \%$ baixo nível de degradação (nascentes 02, 05, 06 e 13), desse modo cerca de $54 \%$ das nascentes sofreram alguma perturbação na vegetação primária.

Como mostra a figura 8 , em que a vegetação próxima a nascente 08 foi degradada e suprimida por ação humana, infringindo o Código Florestal Brasileiro Lei 12.251/12, em que deve se respeitar um raio de $50 \mathrm{~m}$ ao entorno da nascente independente de sua localização. 


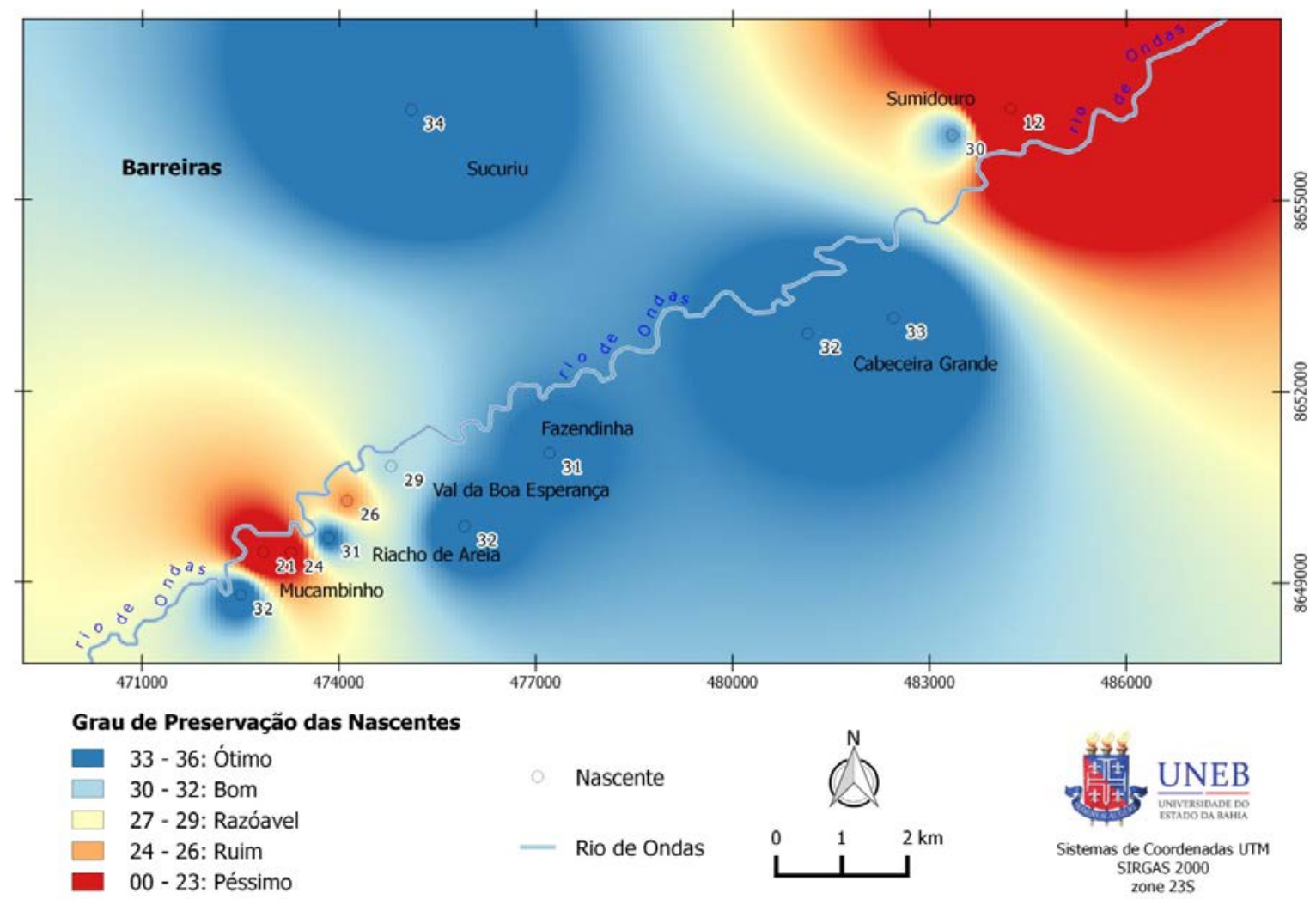

Figura 5 - Mapa de classificação das nascentes quanto aos impactos no Grau de Preservação.

\section{Percentuais dos Parâmetros}

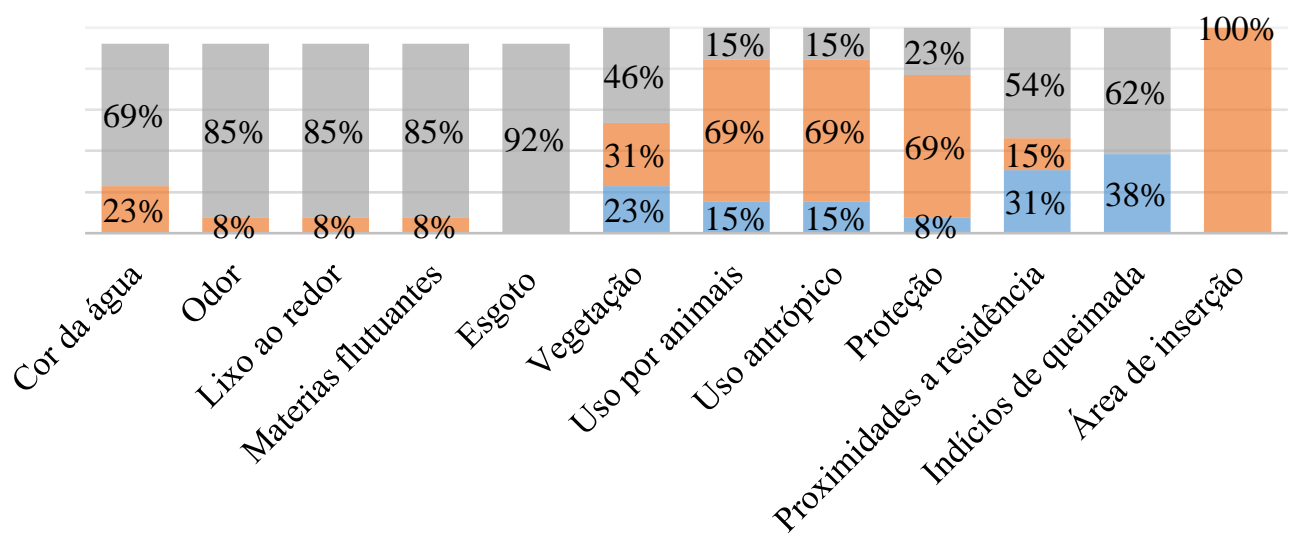

Peso $1 \square$ Peso $2 \square$ Peso 3

Figura 6 - Percentuais dos parâmetros em relação aos pesos dos atributos.

Em um levantamento realizado por Pieroni et al. (2019), nas nascentes da microbacia hidrográfica do Córrego Ibitinga, cerca de 72\% das nascentes apresentaram alta degradação da vegetação, de acordo ao autor o alto nível de degradação se deve ao fato das nascentes estarem localizadas próximas a estradas e, consequentemente se tornam mais vulneráveis a impactos gerados por ação antrópica.
Nas nascentes analisadas, cerca de $61,5 \%$ se encontravam próximas a estradas (nascentes 01, 05, 06, 07, 08, 09, 10 e 13) e nesse caso também foi possível mensurar impactos oriundos dessa proximidade.

De acordo com Gomes et al. (2005) a antropização da vegetação próxima as nascentes ocasionam impactos na proteção, na contenção de processos erosivos, filtragem e influenciam na 

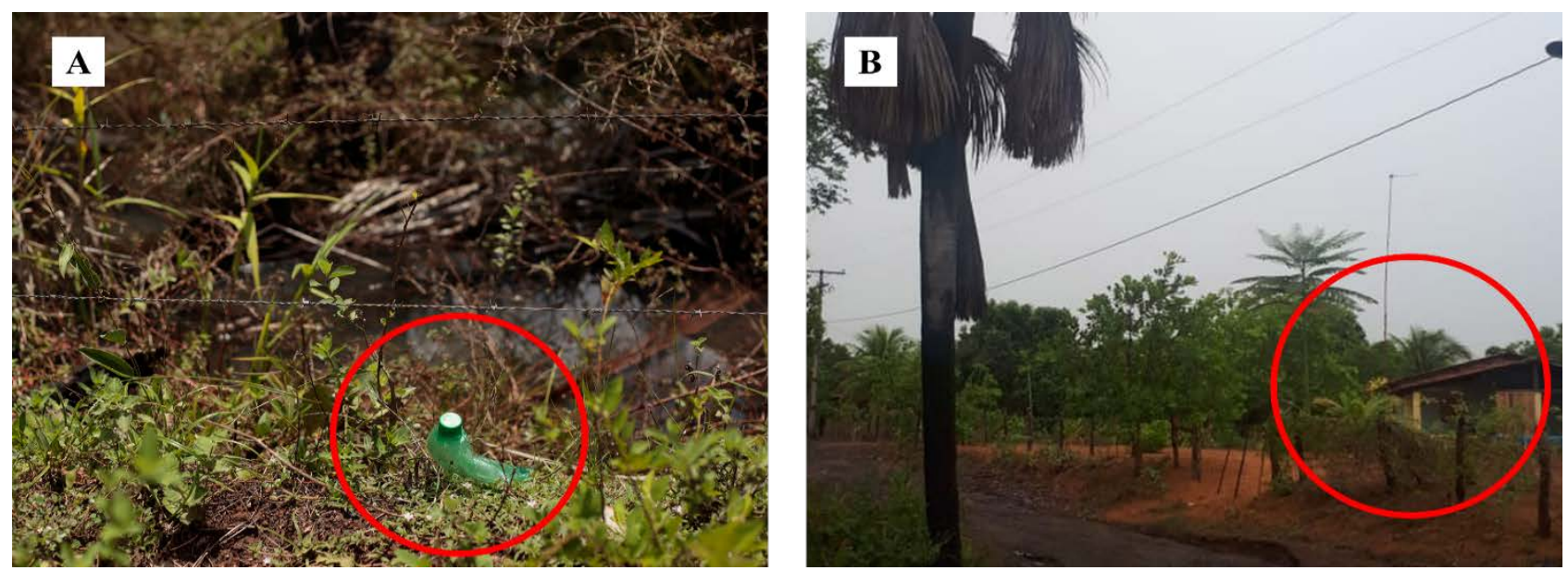

Figura 7 - Presença de lixo ao redor, coloração turva da água e residência próxima a nascente 09 nas fotos A e B.

qualidade da água, ainda segundo os autores foi observado a substituição da vegetação natural por pastagem, gerada pela ocupação de áreas próximas para desenvolvimento de atividades econômicas sem o devido controle e orientação.

Parâmetros como uso pela fauna e antrópico, proteção e queimadas podem influenciar diretamente na conservação da vegetação.

Haja vista que cerca de $69 \%$ das nascentes apresentam indícios de uso pela fauna e antrópico e $15 \%$ das nascentes estava nítido a presença de animais e seres humanos, sendo observados rastros, fezes no local e canos de drenagem de água, esses captadores de água para consumo e irrigação para agricultura familiar (Figura 9A).

Um impacto de expressividade causado pela presença de animais de criação em nascentes, é o pisoteio (Figura 9b), que ocasiona a compactação do solo diminuindo a capacidade de surgência da nascente (Cunha \& Bacani, 2015).

Em estudo realizado por Leal et al. (2017) relataram que $46,7 \%$ das nascentes havia o uso por animais, principalmente evidencias de uso pelo Javali, animal facilmente encontrado no estado de São Paulo, havendo também evidencias de pisoteio por gado. Em relação a proteção ao entorno das nascentes $23 \%$ apresentam proteção adequada com cerca e arame sem haver acesso humano ou animal (nascentes 02, 03 e 12) e 69\% apresentam proteção havendo o acesso humano na área (nascentes 01, 04, 05, 06, 07, 08, 09, 10, 11 e 13) porém a maioria das cercas estão em péssimo estado de conservação e não fazem um isolamento abrangente da área.

Um fator que contribuiu com a proteção das nascentes foi a idealização do Projeto Gota D’água, desenvolvido pela Fundação Mundo Lindo Meio Ambiente com apoio dos moradores para a recuperação de nascentes da bacia do rio de Ondas, as nascentes 02, 03 e 04 fazem parte desse trabalho de recuperação e preservação.

O projeto tem por objetivo levar $0,00001 \%$ de água para o rio São Francisco, tendo em vista que o rio de Ondas integra a bacia do rio São Francisco.

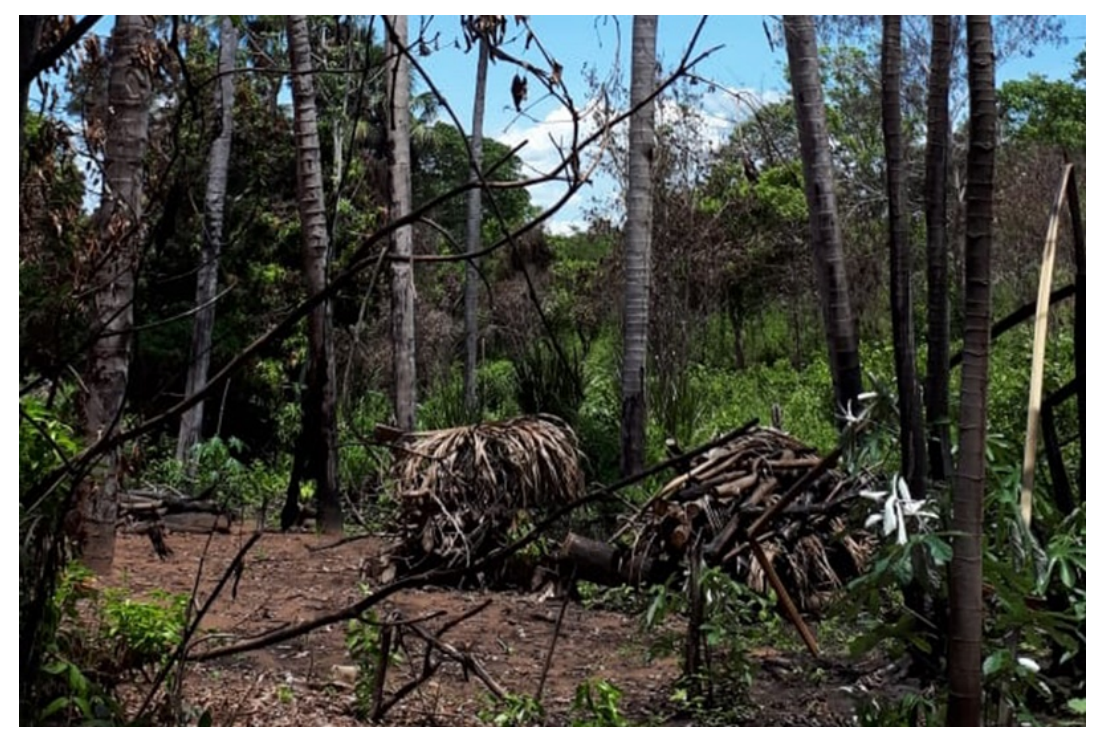

Figura 8 - Imagem de degradação da vegetação próxima a nascente 08. 


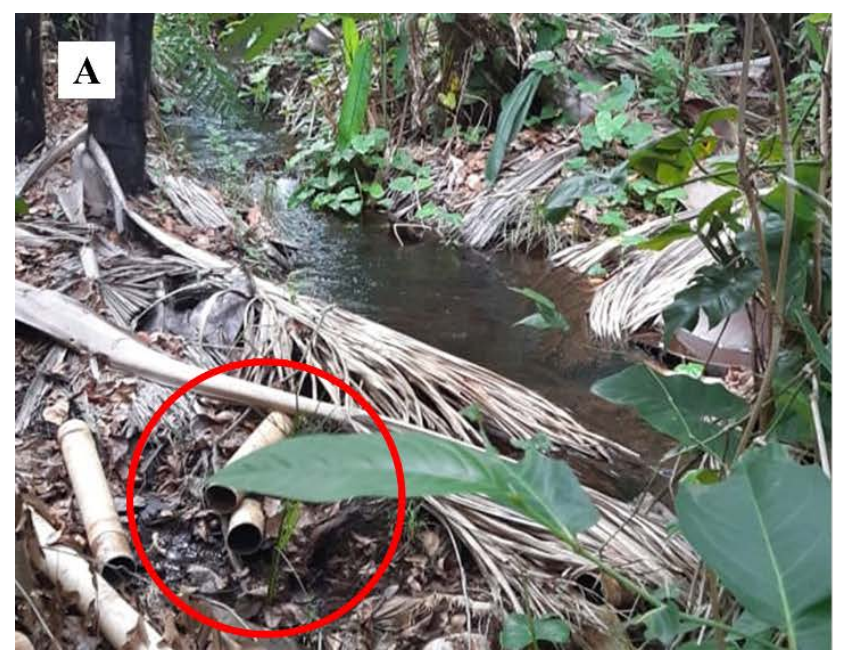

Figura 9 - Imagem de canos de drenagem na nascente 11 (A) e de pisoteio por gado próximo a nascente 03 (B)

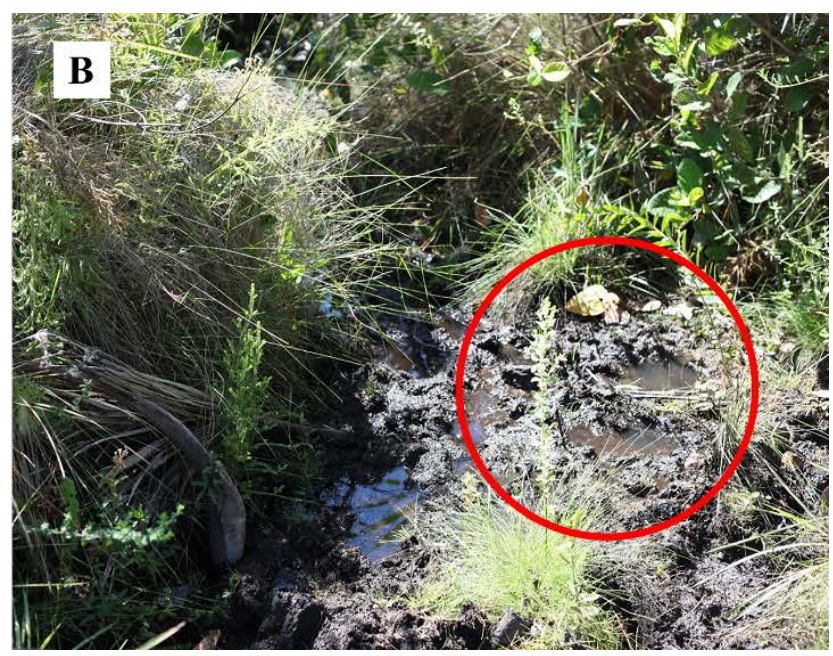

relevância por se tratar de um fenômeno natural no bioma Cerrado em período de seca, porém se acometido de forma criminosa nas áreas que as nascentes estão inseridas causam impactos nocivos a dinâmica hidroambiental das mesmas.

Relatos dos moradores também reafirmaram os impactos provenientes das queimadas, a qual de acordo a Guimarães et al. (2014), destrói a vegetação, principalmente o Buriti (Mauritia flexuosa) espécie nativa de áreas alagadas e com alta distribuição na região, proporciona erosão do solo em decorrência da perda de cobertura vegetal e biomassa, além das cinzas contaminarem a qualidade da água da nascente (Figura 10).

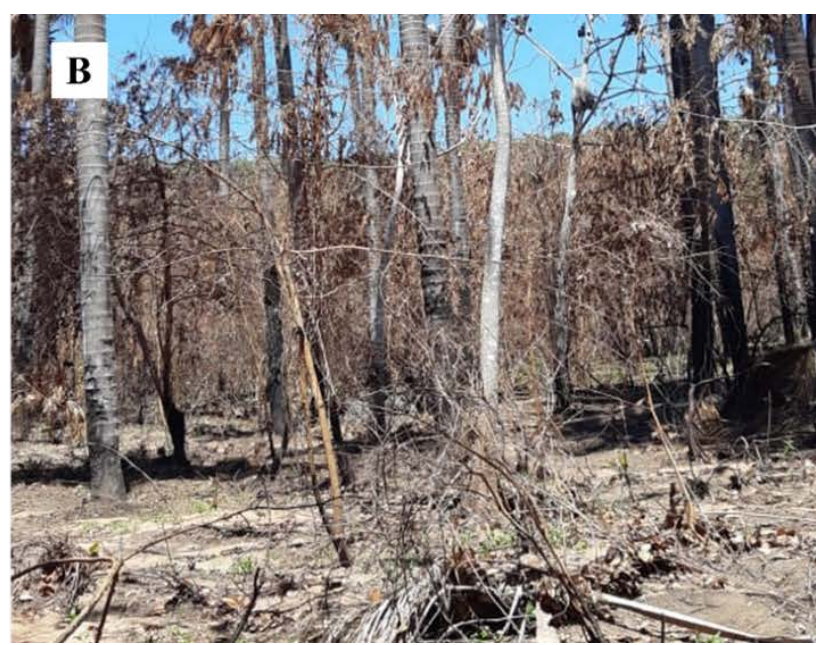

Figura 10 - Imagem da vegetação e buritis queimados ao entorno da nascente 01 fotos A e B.

Cerca de $31 \%$ das nascentes estão localizadas a menos de $50 \mathrm{~m}$ de residências e $100 \%$ das nascentes estão inseridas em áreas particulares. Gomes et al. (2005) relataram que $56,25 \%$ das nascentes analisadas encontravam se próximas as residências ou as residências dentro da APP e 37,5\% estavam inseridas em áreas particulares.

O fator proximidade a residências favoreceu a retirada da vegetação nativa, expôs o solo a processos erosivos e fragilizou o sistema ambiental das nascentes avaliadas.

De acordo aos autores a aproximação das nascentes dessas áreas intensifica os impactos ambientais. Pesquisas desenvolvidas por Felippe \& Magalhães Junior (2012) em estudo realizado no Parque Primeiro de Maio - MG, considerado uma Unidade de Conservação, 
constatou que todas as nascentes estavam a menos de 50m de construções urbanas, os autores relacionaram esse evento ao fato da área do parque ser pequena.

\section{CONSIDERAÇÕES FINAIS}

A partir da identificação e avaliação dos impactos ambientais macroscópicos nas nascentes do rio de Ondas, indicando o Grau de Preservação das nascentes, 69,2\% estão classificadas em Ótimo, Bom e Razoável grau de preservação e 30,7\% estão classificadas como Ruim e Péssimo. Mesmo as nascentes que apresentam um bom grau de preservação, apontam impactos ambientais expressivos e se não mitigados de forma adequada apresentarão consequências para a manutenção hídrica dessa área.

A análise dos parâmetros revelou que a vegetação degradada, queimadas, proximidades a residências e estradas rurais foram os impactos mais frequentes e relevantes nas áreas avaliadas. Dessa forma, se faz necessário a aplicação de medidas mitigadoras, uma vez que estas atuam na minimização dos impactos ambientais e recuperação de áreas degradadas. Tais como o isolamento das APP's ao entorno das nascentes para proteção da vegetação e restrição de acesso humano e animal, plantio de mudas nativas do Cerrado para recuperação da vegetação, manejo consciente na captação de água e retirada dos animais pastoris das nascentes.

A utilização de ferramentas SIGs foi fundamental para a elaboração de mapas, georreferenciamento e processamento de dados referentes a identificação espacial das nascentes.

A interferência nas nascentes através de ações antrópicas de modo inadequado permitiu ao longo de anos a ocorrência de impactos ambientais negativos. É necessário a promoção de políticas públicas que visem proteger os recursos hídricos, que a população tenha conhecimento da legislação ambiental e a dimensão do quão é importante preservar e garantir com qualidade e em abundância os recursos hídricos para todos os seres vivos.

Casos positivos como observados nas nascentes 02, 03 e 04, apoiadas pela Fundação Mundo Lindo Meio Ambiente devem ser expandidos e adotados para as demais nascentes que ainda não foram contempladas pelo projeto Gota D’água.

Desse modo, o levantamento de dados sobre a qualidade ambiental das nascentes, principalmente em períodos de crises hídricas, se torna importante na elaboração de dados a respeito dos recursos hídricos, sendo subsídio em pesquisas que buscam diagnosticar e produzir dados referentes a impactos ambientais, promovendo ações de recuperação, planejamento e manejo no que desrespeita a preservação dos recursos hídricos de forma prática e eficiente.

\section{REFERÊNCIAS}

ANA. Agência Nacional de Água. Conjuntura dos Recursos Hídricos no Brasil, Brasília - DF, 2019. Disp. em: http://conjuntura.ana.gov.br/static/media/conjunturacompleto.bb39ac07.pdf. Acesso em: $21 \mathrm{fev} .2020$.

ALENCAR, V.B; MEIRA, S.A.; MENDES, L.M.S. Áreas de Preservação Permanente no Campus do Itaperi e seu entorno (Fortaleza, Ceará): o uso de técnicas de geoprocessamento no auxílio à proteção ambiental. Planeta Amazônia: Revista Internacional de Direito Ambiental e Políticas Públicas, n. 9, p. 45-59, 2017.

ALMEIDA, R.S.; LATUF, M.O.; SANTOS, P.S. Análise do desmatamento na bacia do rio de Ondas no período de 1984 a 2014, Oeste da Bahia. Caderno Prudentino de Geografia, v. 1, n. 38, p. 41-63, 2016.

ARAÚJO, L.E.; SANTOS, M.J.; DUARTE, S.M; OLIVEIRA, E.M. Impactos ambientais em bacias hidrográficas - caso da bacia do rio Paraíba. Tecnológica, v. 13, n. 2, p. 109-115, 2009.

BANDEIRA, M.N. \& CAMPOS, F.I. Bioma cerrado: relevância no cenário hídrico brasileiro. In: IX SIMPÓSIO NACIONAL DE CIÊNCIA E MEIO AMBIENTE - SNCMA - III CIPEEX, Anápolis, GO. 2018. Anais... Anápolis: CIPEEX, 2018, v. 2, p. 399-409.

BATISTELLA, M.; GUIMARÃES M.; MIRANDA, E.E.; VIEIRA, H.R.; VALLADARES, G.S.; MANGABEIRA, J.A.C.; ASSIS, M.C. Monitoramento da expansão agropecuária na Região Oeste da Bahia. Embrapa Monitoramento por
Satélite-Documentos (INFOTECA-E), Campinas, SP, 2002. BRASIL. Resolução Conama nº 001, de 23 de janeiro de 1986. Dispõe sobre a implementação da Avaliação de Impacto Ambiental como um dos instrumentos da Política Nacional do Meio Ambiente. Diário Oficial da união, Brasília, DF, 23 jan. 1986. Disponível em: http://www2.mma.gov.br/port/cona ma/res/res86/res0186.html. Acesso em: 20 nov. 2018.

BRASIL. Lei n ${ }^{\circ} 12.651$ de maio de 2012. Dispõe sobre a proteção de vegetação nativa. Diário Oficial da União, Brasília, DF, 25 mai. 2012. Disp. em: http://www.planalto.gov.br/ccivil_03/ _Ato2011-2014/2012/Lei/L12651.htm. Acesso em: 17 nov. 2018.

CONEJO, J.G.L.; DA COSTA, M.P.; TEIXEIRA, A.L.D.F. Panorama da qualidade das águas superficiais no Brasil. Superintendência de Planejamento de Recursos Hídricos, 2005. CREMONEZ, F.E.; CREMONEZ, P.A.; FEROLDI, M.; CAMARGO, M.P.; KLAJN, F.F.; FEIDEN. Avaliação de impacto ambiental: metodologias aplicadas no Brasil. Revista Monografias Ambientais, v. 13, n. 5, p. 3821-3830, 2014.

CUNHA, E.R. \& BACANI, V.M. Geoprocessamento e SIG aplicado na identificação dos conflitos de uso da terra e legislação ambiental na bacia hidrográfica do córrego Indaiá, Aquidauana-MS. In: XVII SIMPÓSIO BRASILEIRO DE SENSOREAMENTO REMOTO-SBSR, João Pessoa-PB. 2015. Anais...Três Lagoas-MS: INPE, 2015. p. 0842 - 0849. FALEIRO, F.G. \& FARIA, A.L.N. Savanas: desafios e 
estratégias para o equilíbrio entre sociedade, agronegócio e recursos naturais. 1. ed. Embrapa Cerrados: Planaltina, DF, 2008 FELIPPE, M.F. \& MAGALHÃES JR, A.P. Impactos ambientais macroscópicos e qualidade das águas em nascentes de parques municipais em Belo Horizonte- MG. Revista Geografias, v. 8, n. 2, p. 8-23, 2012.

FISTAROL, P.H.B.; BRANDOLFF, R.S.; SANTOS, J.Y.G. Análise fisiográfica da Bacia do Rio de Ondas - BA. In: XVII SIMPÓSIO BRASILEIRO DE SENSORIAMENTO REMOTO - SBSR, João Pessoa - PB, 2015. Anais...São José dos Campos: INPE, 2015. p. 5469 - 5476.

GOMES, P.M.; MELO, C.; VALE, V.S. Avaliação dos impactos ambientais em nascentes na cidade de Uberlândia-MG: análise macroscópica. Sociedade \& Natureza, v. 17, n. 32, 2005.

GOMES, E.C.F.; JESUS, E.N.; OLIVEIRA, N.N.; JÚNIOR, L.G.; CABRAL, F.G.S.; RESENDE, M.S.R. A nova legislação ambiental brasileira e seus efeitos sobre a reestruturação de nascentes e remanescentes florestais. Pesquisa Florestal Brasileira, v. 38, 2018.

GUIMARÃES, P.P.; SOUZA, S.M.D.; FIEDLER, N.C.; SILVA, A.G. Análise dos impactos ambientais de um incêndio florestal. Agrarian Academy. Centro Científico Conhecer, Goiânia, Goiás-Brasil, v. 1, n. 01, p. 38-60, 2014.

IBGE. Instituto Brasileiro de Geografia e Estatística. Barreiras, Bahia, Brasil- Censo 2017. Disp. em: https://cidades.ibge. gov.br/brasil/ba/barreiras/panorama. Acesso em: 28 out. 2018.

IBGE. Instituto Brasileiro de Geografia e Estatística. Geociências: Downloads. 2010. Disp. em: https://www.ibge.gov.br/geociencias/downloadsgeociencias.html. Acesso em: 29 já. 2020.

INCRA. Instituto Nacional de Colonização e Reforma Agrária. Acervo Fundiário. 2010. Disponível em: http:// acervofundiario.incra.gov.br/acervo/acv.php. Acesso em: 29 jan. 2020.

LEAL, M.S.; TONELLO, K.C.; DIAS, H.C.T.; MINGOTI, R. Caracterização hidroambiental de nascentes. Ambiente \& Água-An Interdisciplinary Journal of Applied Science, v. 12, n. 1, 2017.

MAGALHÃES, E.C \& BRASILEIRO, R.S. Análise geográfica do uso e ocupação do solo na área da bacia hidrográfica do rio de Ondas no período de 1975 á 2015 - Barreiras-Bahia-Brasil. In: VIII SIMPÓSIO INTERNACIONAL DE GEOGRAFIA AGRÁRIA E IX SIMPÓSIO NACIONAL DE GEOGRAFIA AGRÁRIA, 2017, Curitiba - Paraná. Anais...Curitiba: SINGA, 2017. Issn: 1980-4555.

MMA. Ministério do Meio Ambiente. Downloads de dados geográficos. 2010. Disp. em: http://mapas.mma.gov.br/i3geo/ datadownload.htm. Acesso em: 29 jan. 2020.

MMA. Ministério do Meio Ambiente. O Bioma Cerrado. 2020. Disp. em: https://www.mma.gov.br/biomas/cerrado. Acesso em: 18 Abr. 2020.

MOREIRA, M.C \& SILVA, D.D. Atlas hidrológico da bacia hidrográfica do rio Grande - Barreiras, BA: Editora Gazeta Santa Cruz, 2010.

NERES, N.G.C. SOUZA, P.A.; SANTOS, A.F.; GIONGO, M.; BARBOSA, L.L. Avaliação ambiental e indicação de medidas mitigadoras para a nascente do córrego mutuca, Gurupi - TO. Enciclopédia Biosfera, v. 11, n.2 1, 2015.

OLIVEIRA NETA, M.R. Recursos hídricos: água um bem precioso para a humanidade Conteúdo Jurídico, Brasília DF, 2013. Disp. em: https://conteudojuridico.com .br/consulta/Artigos/34680/recursos-hidricos-agua-um-bemprecioso-para-a-humanidade. Acesso em: 02 fev. 2020.

OLIVEIRA, P.C.M.; OLIVEIRA, B.T.A.; DIAS, J.S.; MOURA, M.N.; SILVA, B.M.; BARBOSA, S.V.; FELIPPE, M.F. Avaliação macroscópica da qualidade das nascentes do campus da Universidade Federal de Juiz de Fora. Revista de Geografia-PPGEO-UFJF, v. 3, n. 1, 2013.
PENA. R.F.A. Águas Subterrâneas. Goiânia - GO, 2020. Disp. em: https://mundoeducacao.bol.uol.com.br/geografia/Aguassubterraneas.htm. Acesso em: 20 abr. 2020.

PIERONI, J.P.; BRANCO, K.G.R.; DIAS, G.R.V.; FERREIRA, G.C. Avaliação do estado de conservação de nascentes em microbacias hidrográficas. Geociências, v. 38, n. 1, p. 185 - 193, 2019.

QGIS 2.8. Análise Espacial Interpolação. 2020. Disp. em: https://docs.qgis.org/2.8/pt_BR/docs/gentle_gis_introduction/s patial_analysis_interpolation.html. Acesso em: 02 fev. 2020

REIS, S.L.S. Desenvolvimento e natureza: a dinâmica de ocupação do cerrado e repercussões ambientais na região agroexportadora do oeste baiano. Salvador, 2014. 138 p. Dissertação (Mestrado em Geografia) - Universidade Federal da Bahia, Salvador, 2014.

SMA. Secretaria de Estado do Meio Ambiente, Departamento de Proteção da Biodiversidade. Cadernos da Mata Ciliar Preservação e recuperação das nascentes de água e de vida, São Paulo - SP, n. 1, 2009. Disp. em: https:// www.infraestruturameioambiente.sp.gov.br/educacaoambienta 1/prateleira-ambiental/cadernos-da-mata-ciliar-1-preservacaoe-recuperacao-das-nascentes-de-agua-e-de-vida/. Acesso em: 15 set. 2019.

SÁNCHEZ, L.E. Avaliação de impacto ambiental: conceitos e métodos. 2. ed. Oficina de Textos. São Paulo-SP, 2013.

SANO, S.M.; ALMEIDA, S.P.; RIBEIRO, J.F (ed.). Cerrado: Ecologia e Flora, v 1. Embrapa-Cerrados: Brasília, Brasil, 2008.

SANTANA, O.A.; CARVALHO JÚNIOR, O.A.; GOMES, R.A.T.; CARDOSO, W.S; MARTINS, E.S.; PASSO, D.P.; GUIMARÃES, R.F. Distribuição de espécies vegetais nativas em distintos macroambientes na região do oeste da Bahia. Revista Espaço e Geografia, v. 13, n. 2, 2010.

SANTOS, C.A.P; SANO, E.E; SANTOS, P.S. Fronteira agrícola e a dinâmica de uso e ocupação dos solos no oeste da Bahia. ACTA Geográfica, Boa Vista, v. 12, n. 28, p. 17-32, 2018.

SEMA. Secretária de Meio Ambiente Cartilha: Nascentes protegidas e recuperadas. Curitiba, PR., 2010.

SENAR - Serviço Nacional de Aprendizagem Rural. A importância da propriedade rural na produção e na preservação da água de qualidade. Curso de proteção a nascente, Brasília - DF, 2015. Disp. em: https://www.cnabrasil.org.br/senar. Acesso em: 18 out. 2019.

SOARES, J.A.B.; CAMARGO, G.; GIONGO, P.R.; GIONGO, A.M.M.; GOMES, L.F. Identificação e caracterização das nascentes dos rios de Santa Helena de Goiás e a relação da oferta de água com usos do solo. Brazilian Applied Science Review, v. 2, n. 6, p. 1962-1974, 2018.

SOBRAL, I.S.; SANTANA, R.K.O.; GOMES, L.J.; RIBEIRO, G.T.; SANTOS, J.R.; COSTA, M. Avaliação dos impactos ambientais no Parque Nacional Serra de Itabaiana-SE. Caminhos de Geografia, v. 8, n. 24, 2007.

SOUZA, P.A. GLORIA, A.P.S.; GONÇALVES, D.S.; SANTOS, A.D. Metodologias de avaliação de impactos ambientais da APP, Rancho Tutty Falcão Gurupi-TO. Enciclopédia Biosfera, v. 13, n. 24, 2016.

ZEFERINO, M.C. Medidas Mitigadoras e Compensatórias de Impactos Ambientais. Viçosa - MG. 22 mar. 2018. Disp. em: http://www.matanativa.com.br/blog/medidas-mitigadoras-ecompensatorias-de-impactos-ambientais/. Acesso em: 22 jan. 2020 .

Submetido em 27 de maio de 2020 Aceito para publicação em 15 de agosto de 2020 